\title{
Self-Healing Single-Ion Conducting Polymer Electrolyte Formed via Supramolecular Networks for Lithium Metal Batteries
}

Huihui Gan, Yong Zhang, Shaoqiao Li, Liping Yu, Jirong Wang, and Zhigang Xue*

Key Laboratory of Material Chemistry for Energy Conversion and Storage, Ministry of Education, Hubei Key Laboratory of Material Chemistry and Service Failure, School of Chemistry and Chemical Engineering, Huazhong University of Science and Technology, Wuhan 430074, China.

E-mail address: zgxue@mail.hust.edu.cn (Z.Xue)

Number of pages: 7

Number of figures: 10

\section{Table of Contents}

Figure S1. Synthetic scheme of SSPSILi monomers .........................S2

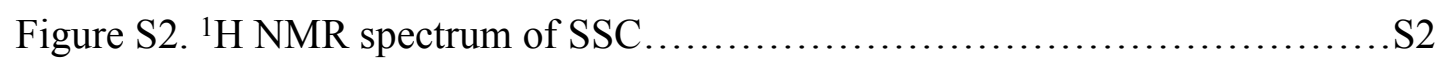

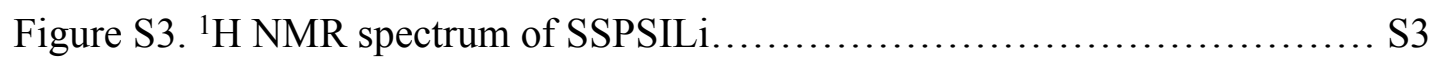

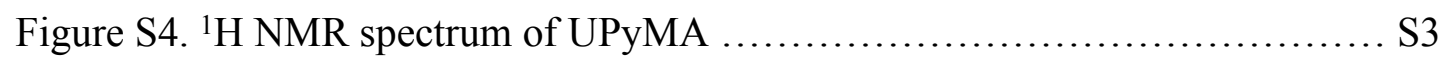

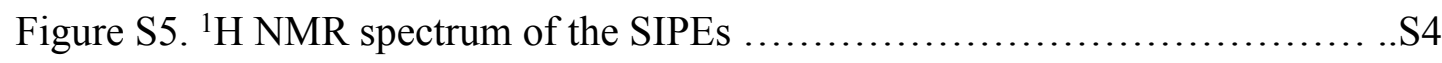

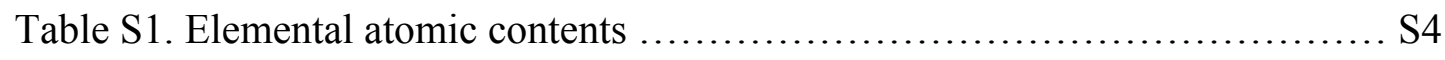

Figure S6. FT-IR spectra of the SIPE membranes............................ . 5

Figure S7. EDS-mapping images of the SIPE membranes..................... S6

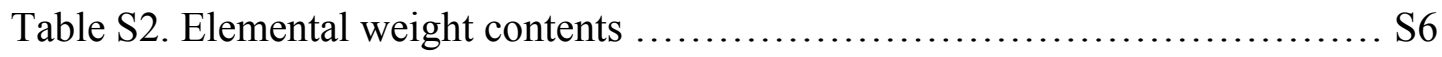

Table S3. Properties of SIPEs ......................................... S7

$\begin{array}{llll}\text { Figure } & \text { S8. } & \text { LSV } & \text { curves }\end{array}$

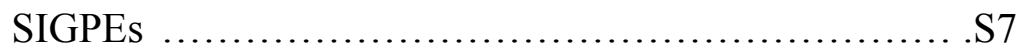

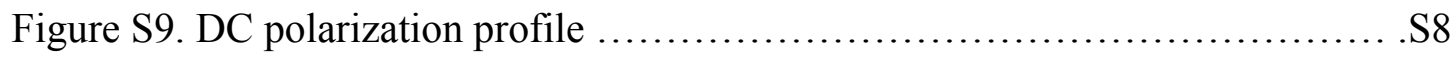

Figure S10. Rate performance of the cell................................. S8 


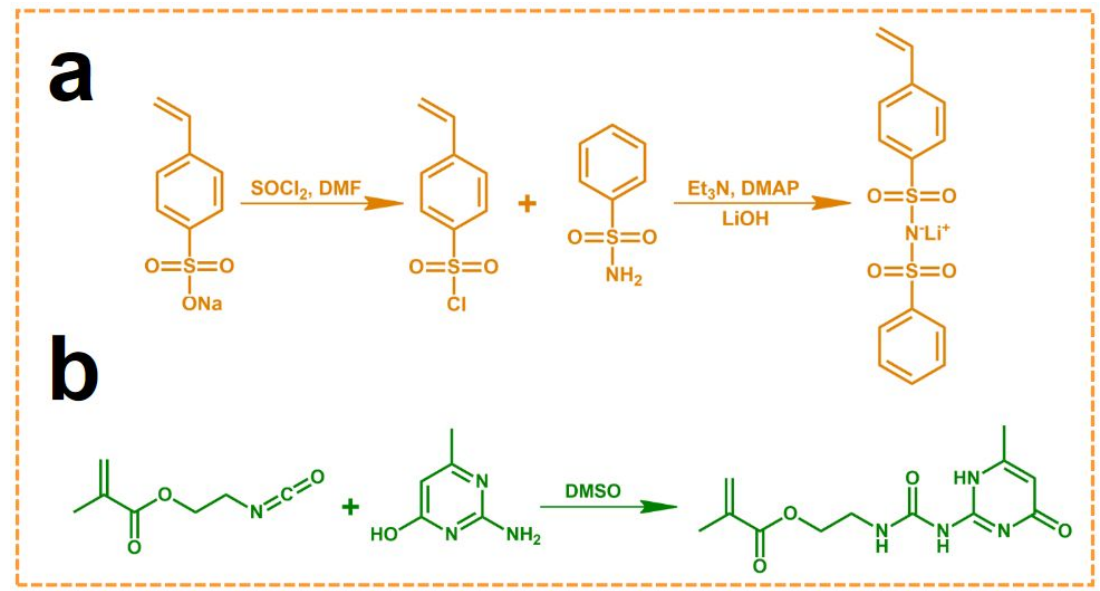

Figure S1. The synthetic scheme of SSPSILi monomers (a) and UPyMA monomers (b).

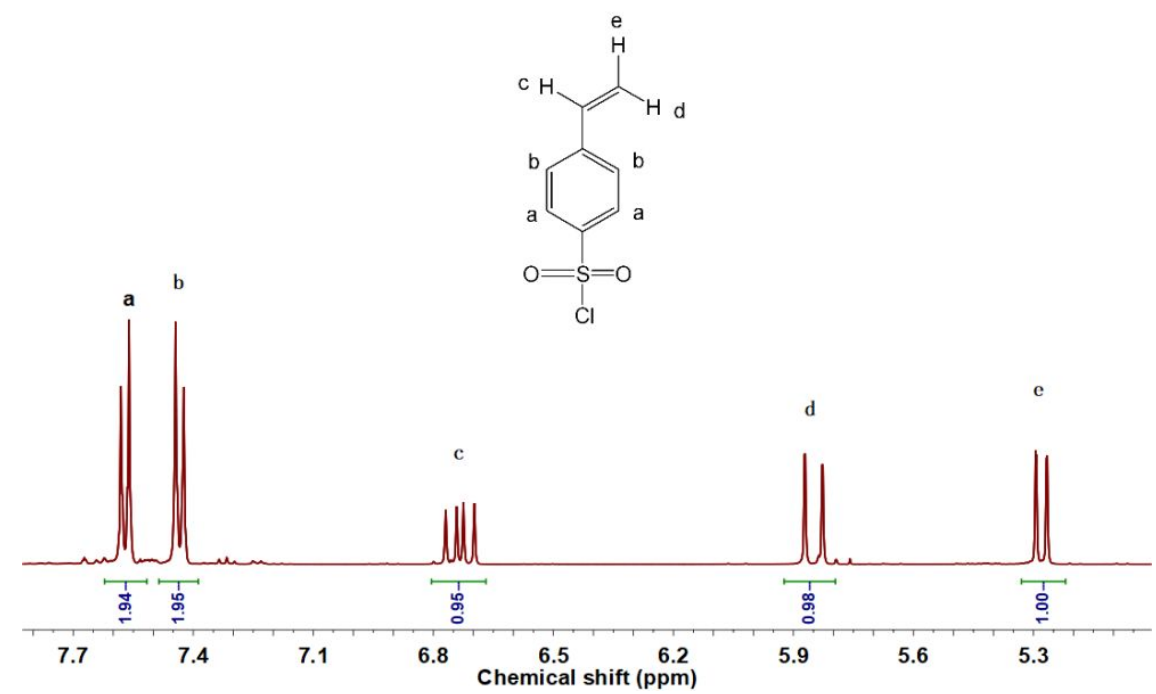

Figure S2. ${ }^{1} \mathrm{HNMR}$ spectrum of SSC (DMSO- $d_{6}$ ). 


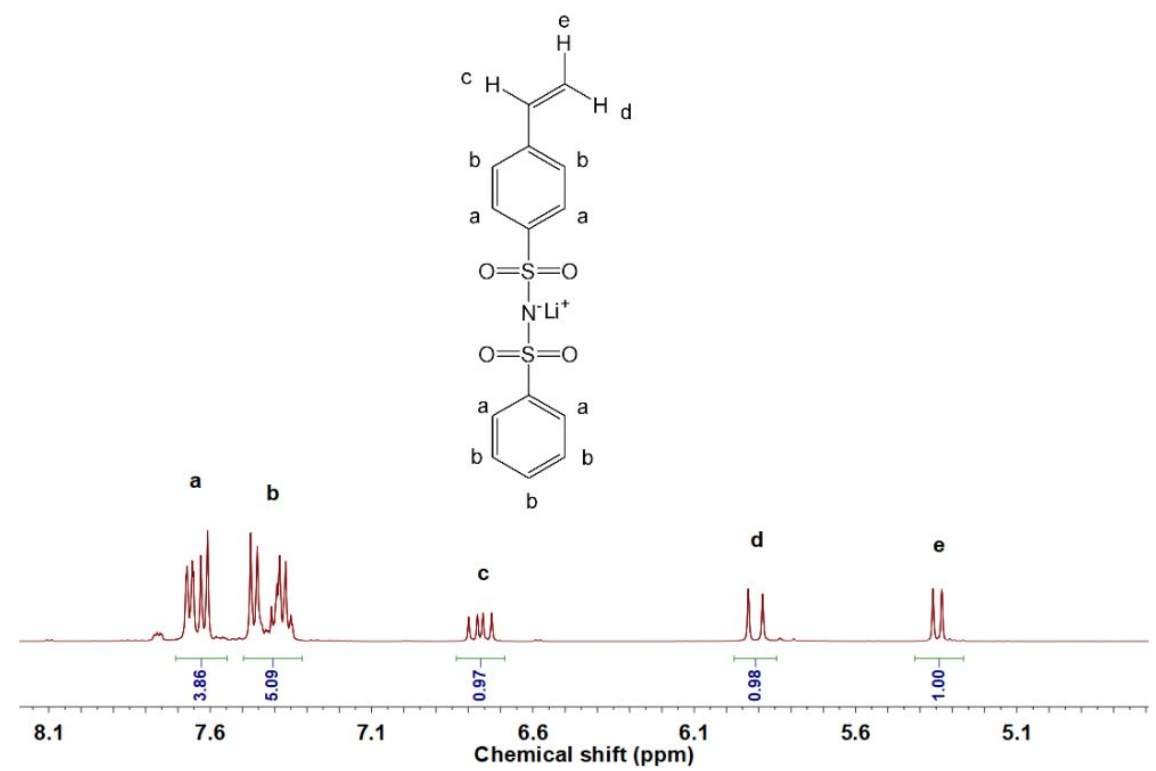

Figure S3. ${ }^{1} \mathrm{HNMR}$ spectrum of SSPSILi $\left(\mathrm{DMSO}-d_{6}\right)$.

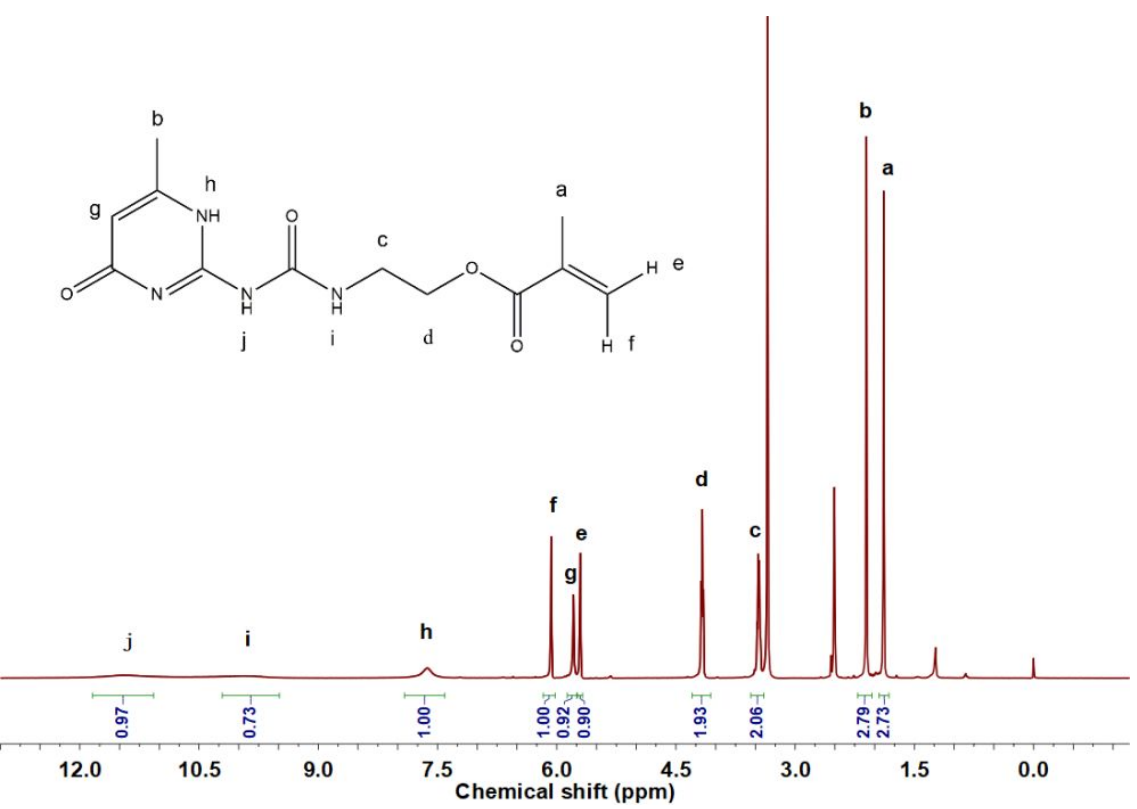

Figure S4. ${ }^{1} \mathrm{HNMR}$ spectrum of UPyMA (DMSO- $d_{6}$ ). 


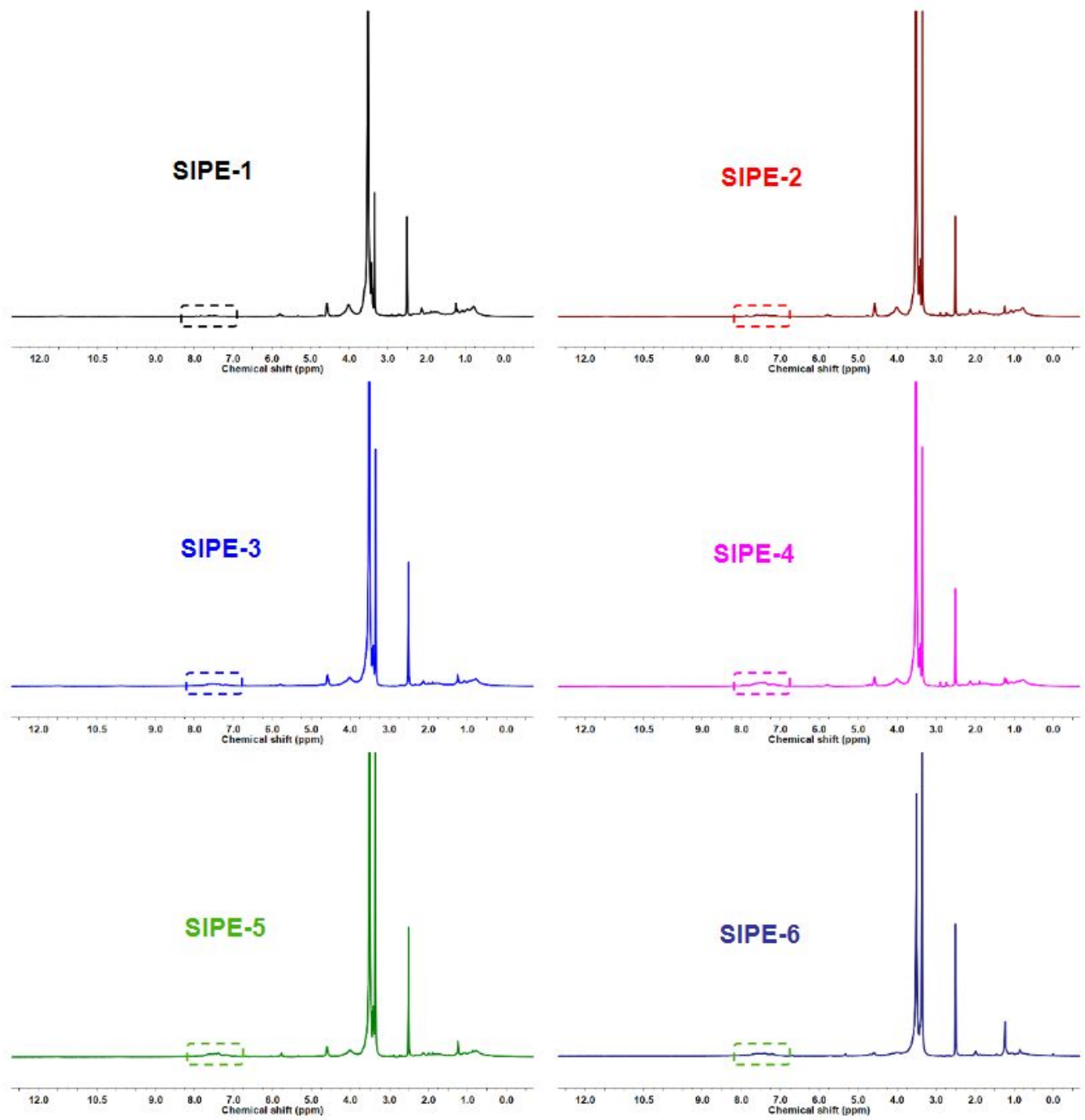

Figure S5. ${ }^{1}$ HNMR spectrum of the SIPEs $\left(\right.$ DMSO- $\left.d_{6}\right)$.

Table S1. Elemental atomic contents (\%) of the SIPE membranes.

\begin{tabular}{ccccc}
\hline Sample & $\mathrm{C}$ & $\mathrm{O}$ & $\mathrm{N}$ & $\mathrm{S}$ \\
\hline SIPE-1 & 64.08 & 32.65 & 2.90 & 0.36 \\
SIPE-2 & 64.15 & 31.81 & 3.11 & 0.93 \\
SIPE-3 & 64.78 & 30.63 & 3.08 & 1.50 \\
SIPE-4 & 64.07 & 30.04 & 3.63 & 2.26 \\
SIPE-5 & 68.83 & 24.27 & 1.32 & 5.58 \\
SIPE-6 & 66.50 & 23.79 & 2.48 & 7.22 \\
\hline
\end{tabular}



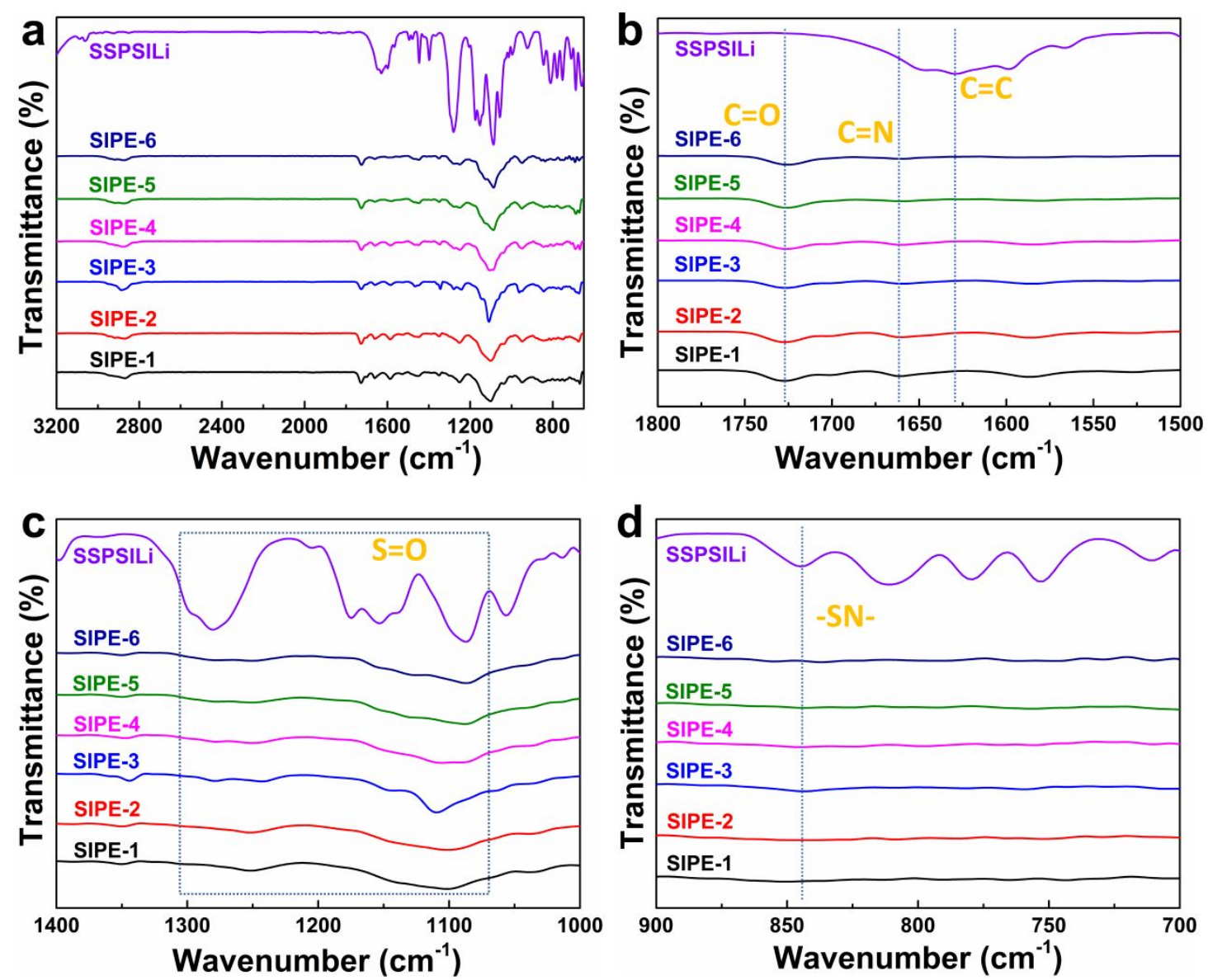

Figure S6. FT-IR spectra of the SIPE membranes. Wavenumber range from $3200-700 \mathrm{~cm}^{-1}$ (a). $1800-1500 \mathrm{~cm}^{-1}$ (b). $1400-1000 \mathrm{~cm}^{-1}$ (c). and $900-700 \mathrm{~cm}^{-1}$ (d). 


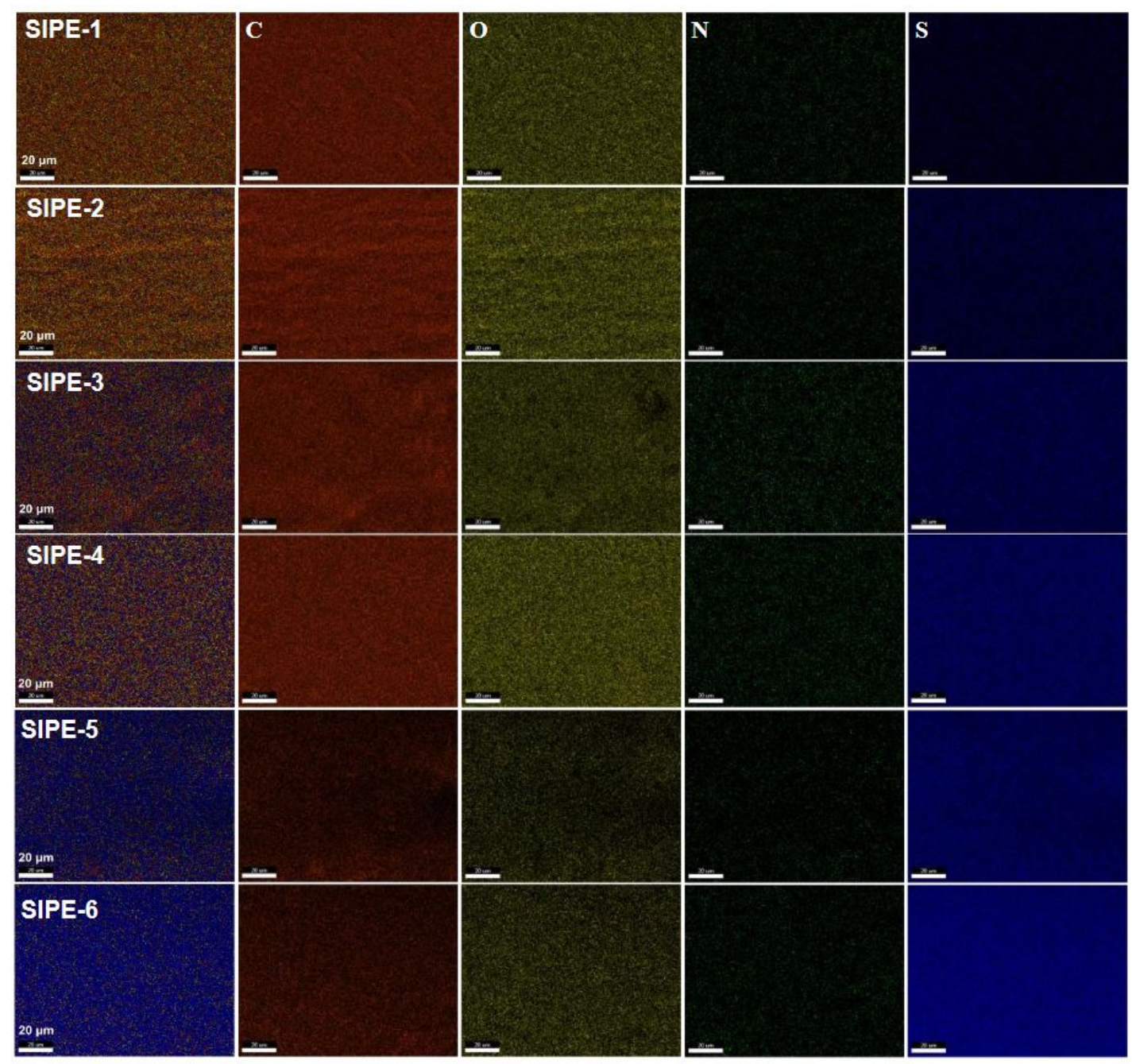

Figure S7. The EDS-mapping images of the SIPE membranes.

Table S2. Elemental weight contents (\%) of the SIPE membranes.

\begin{tabular}{ccccc}
\hline Sample & $\mathrm{C}$ & $\mathrm{H}$ & $\mathrm{N}$ & $\mathrm{S}$ \\
\hline SIPE-4 & 52.24 & 7.377 & 3.19 & 3.545 \\
SIPE-5 & 52.54 & 7.149 & 2.54 & 4.243 \\
SIPE-6 & 51.84 & 6.996 & 2.49 & 5.227 \\
\hline
\end{tabular}


Table S3. The information of molecular weight, thermal, mechanical and electrochemical properties for the SIPE.

\begin{tabular}{cccccccc}
\hline Sample & $M_{\mathrm{n}}$ & $M_{\mathrm{w}}$ & $M_{\mathrm{w}} / M_{\mathrm{n}}$ & $T_{\mathrm{g}}$ & Stress & Strain & Ionic conductivity \\
& $\left(\mathrm{g} \mathrm{mol}^{-1}\right)$ & $\left(\mathrm{g} \mathrm{mol}^{-1}\right)$ & & $\left({ }^{\circ} \mathrm{C}\right)$ & $(\mathrm{MPa})$ & $(\%)$ & $\left(\mathrm{S} \mathrm{cm}^{-1}\right.$ at $\left.60{ }^{\circ} \mathrm{C}\right)$ \\
\hline SIPE-1 & 63000 & 74800 & 1.19 & -49.6 & 0.045 & 393 & $1.88 \times 10^{-6}$ \\
SIPE-2 & 72300 & 89900 & 1.24 & -47.3 & 0.065 & 427 & $9.78 \times 10^{-6}$ \\
SIPE-3 & 63000 & 78500 & 1.25 & -40.6 & 0.173 & 359 & $1.86 \times 10^{-5}$ \\
SIPE-4 & 62800 & 74000 & 1.18 & -30.6 & 0.235 & 356 & $1.06 \times 10^{-5}$ \\
SIPE-5 & 73100 & 98900 & 1.35 & -23.6 & 0.514 & 288 & $1.40 \times 10^{-5}$ \\
SIPE-6 & 66100 & 76100 & 1.15 & -16.4 & 0.739 & 99 & $5.36 \times 10^{-6}$ \\
\hline
\end{tabular}

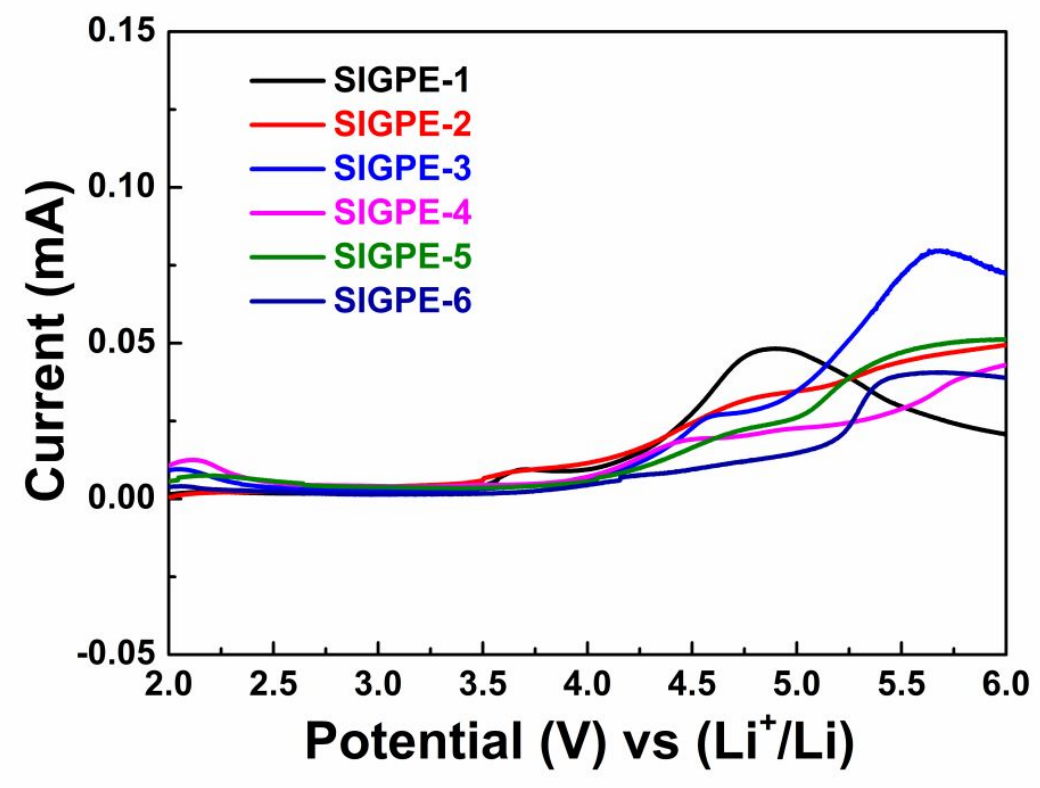

Figure S8. LSV at a scan rate of $1 \mathrm{mV} \mathrm{s}^{-1}$ at $60{ }^{\circ} \mathrm{C}$. 


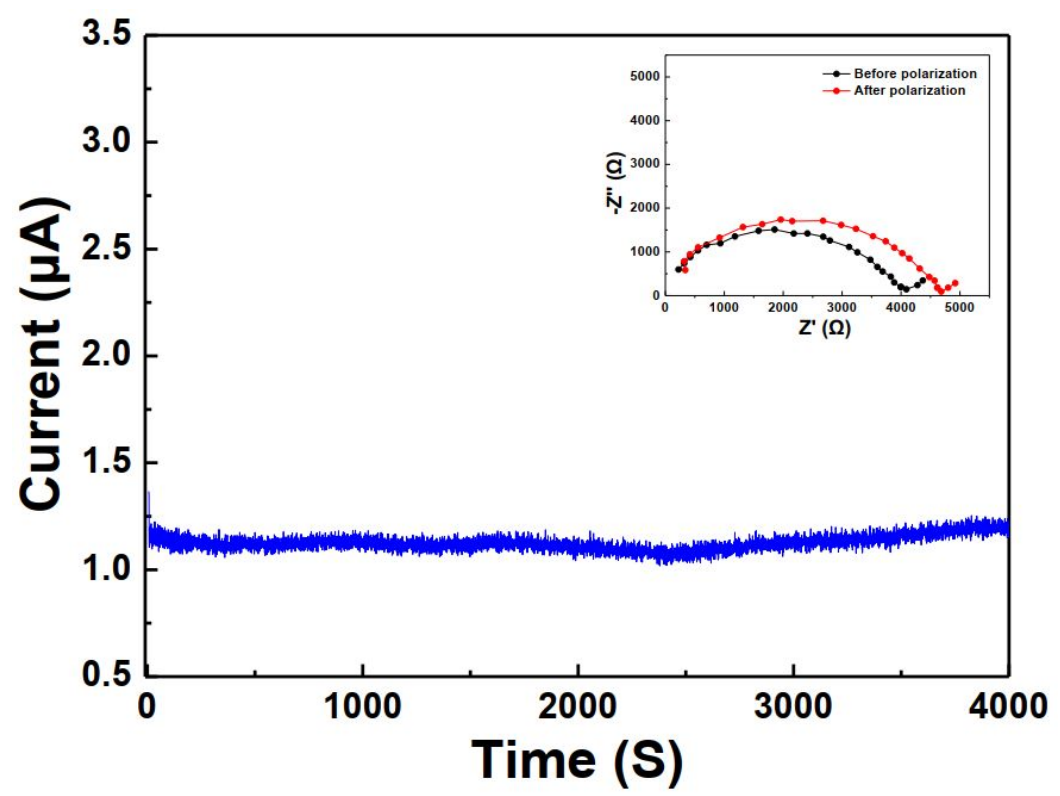

Figure S9. DC polarization profile of the Li/SIGPE-5 membrane/Li symmetric cell under a 10 $\mathrm{mV}$ polarization voltage at $60{ }^{\circ} \mathrm{C}$ and the inset shows the $\mathrm{AC}$ impedance plots of the Li/SIGPE-5 membrane/Li symmetrical cell before and after polarization.

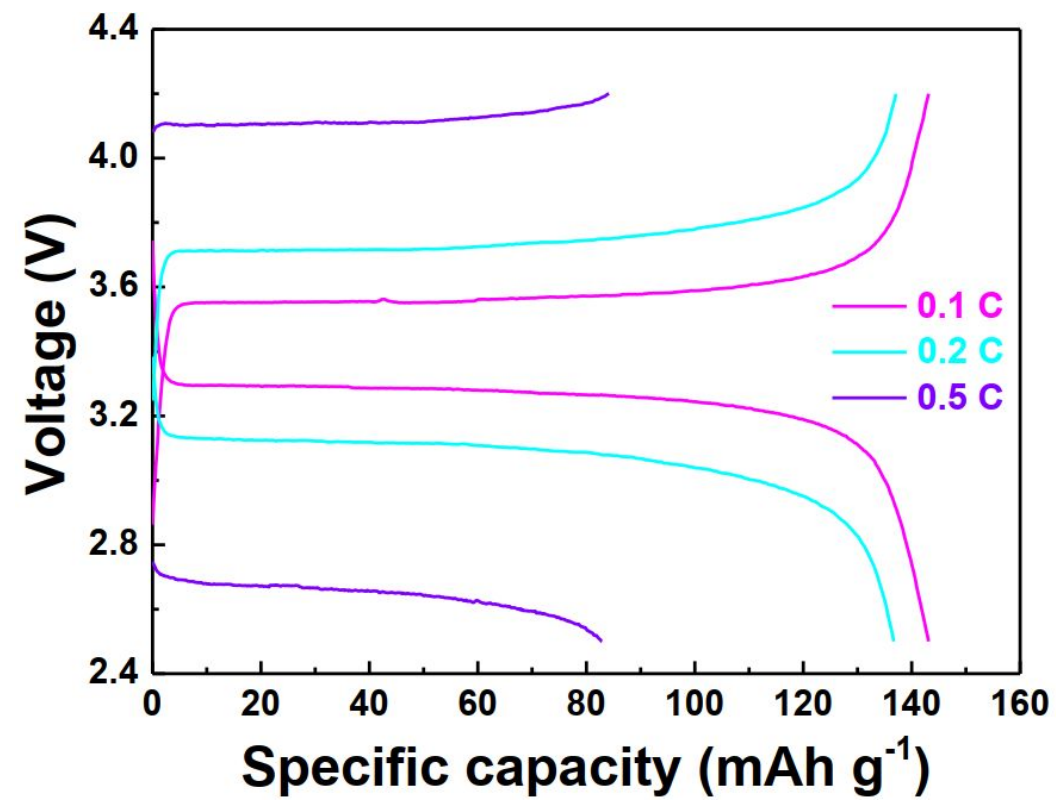

Figure S10. Rate performance of the cell at $60^{\circ} \mathrm{C}$ at different rates of $0.1 \mathrm{C}, 0.2 \mathrm{C}$ and $0.5 \mathrm{C}$. 